\title{
Book Review of
}

\section{David L. Weakliem. Public Opinion.}

by

\author{
NATE BREZNAU \\ University of Bremen
}

This is a preprint version of:

Breznau, Nate. 2021. "David L. Weakliem. Public Opinion.” Public Opinion Quarterly 85(1):248-51. doi: 10.1093/poq/nfaa055.

In the book Public Opinion, David L. Weakliem provides a didactic and short overview of the topic as per the title. It should be useful for undergraduate and graduate students to familiarize themselves with public opinion as a broad, longstanding, interdisciplinary area of research. Weakliem inserts a short segment on the role of sociology in public opinion, and Chapter Two is rather sociological in its focus, but the remaining chapters deal especially with politics. As such, this book serves sociology, political science, communications and various political studies subfields. Is it like an unindexed compendium for those knowing little about public opinion but needing to familiarize themselves with concepts and data sources, as Weakliem weaves in essentially all of the major US and several international opinion surveys in his examples. The caveat is a strong focus on the US, meaning that students in/of the Global South or rich "nonWestern" countries may find little to relate to - and, in the worst case, may get the false impression that public opinion is not really studied outside of the US. The book does not present anything new about the topic, except for incorporating examples from very recent data sources; however, the book's implicit didactic goals preclude the need for new insights in this area.

In a way, this book covers more and in fewer pages than previous books such as Lippmann's (1997[1922]) identically titled classic or Zaller's (1992) more recent and empirically focused authoritative effort. As with much of the last century's public opinion literature, these previous books grappled with subjective perceptions, interpretivism and an epistemological problem of whether anything like "public opinion" actually exists, as suggested by Zaller's intentional use of the term "mass" in lieu of "public" opinion in his book title. Weakliem touches upon some concepts in this epistemological mire in Chapter One but brings the focus back to survey research where it remains for the rest of the book. As such, he takes a modern and ostensibly positivist position that public opinion exists and surveys are well-suited to measure it.

Focusing on surveys has didactical advantages because they are ideally suited to discussing nonresponse and population sampling. Moreover, they are the mainstream of public opinion data, and Weakliem draws on them to bring public opinion to life. For example, in discussing the advent of polling and how to measure opinion changes, he points out that in the US "in June 1937, 70 percent said that they were in favor of labor unions and 22 percent said they were not; in October 1938, 58 percent were in favor and 28 percent were not." His simple examples help bring public 
opinion to life for the reader. Of course, the narrow focus comes at the cost of missing the universe of non-survey-based research such as the recent eruption of quantitative text analysis using internet-mined big data (Theocharis and Jungherr 2020), or the promising avenues of structured qualitative research (Cramer 2016).

Chapter Two is the most sociological. It provides a tour of public opinion through lenses of group dynamics and modernization/industrialization. For example, it frames group differences in opinion and voting patterns across class, race and religion and their bases in Marxian-conflict, homophiliy and structural conditions. Chapter Three tackles ideology, in particular, left-right subjective political ideology — meaning "Democrat-Republican" given the US focus. The chapter describes key studies and concepts from Free and Cantril's operational ideology to Converse's attitude constraint. This leads to a discussion of polarization using examples of abortion and inter-party animosity in the US (Figures 3.1 and 3.2). The chapter concludes with the idea that the division of ideology by left-right and economic versus social issues may be over simplified, but is still salient. Weakliem cites one study that suggests European parties continue to follow the leftright divide and that the working-class tend to take "right-wing positions on both economic and social issues" (p. 80). This is a misrepresentation of the literature and state of affairs in Europe where populist parties emerged that are socially very right but economically more left in terms of state redistribution and social security, albeit only for non-immigrants or non-Muslims (Eger and Valdez 2015), something known as the progressive's dilemma (Kulin, Eger, and Hjerm 2016) or welfare chauvinism (Eger and Breznau 2017). This may sadly reinforce a US-dominated public opinion research arena that not only pays little attention to Europe, but is likely to misunderstand what is happening there.

Chapters Four and Five discuss short-term and long-term changes in public opinion. The former covers a broad range of useful topics, including the multilevel problem of observing individuals but measuring societies, thermostatic feedback, parallel publics, social movements, framing, and the roles of macro-economics and economic inequality. It concludes with poignant examples of heated US topics such as racial equality, gay marriage and minimum wages. The latter returns to modernization, and brings up the role of historical trajectories. It is far shorter than the previous. To its credit, it touches on immigration and globalization, but it does so without tapping the universe of literature on these topics and their linkages to public opinion. Weakliem's delineation of public opinion into short-term and long-term perhaps misses an opportunity to integrate more social psychology and institutional theoretical perspectives. There are possibly two qualitatively different objects of focus, as researchers often distinguish malleable "attitudes" or "preferences" (analogous to what Weakliem calls "short-term" opinion change) from more stable and institutionalized "values" or "norms" (like Weakliem's "long-term" opinion). In fairness, the terseness of the book is an asset, so introducing more concepts or disciplinary integrations might disparage this; but, psychologists or social psychologists are not the best audience for the book as a result.

The final chapter is somewhat dubiously titled "Public Opinion and Liberal Democracy", and it reads more like two separate chapters. The opening paragraph claims to explain the reasons for democratic backsliding in recent years and launches into a discussion of populism in Europe and the United States. It provides a wealth of information on basic trends and sources of populism, and I imagine assigning it in undergraduate or graduate courses. However, as the final chapter of 
a book titled "Public Opinion" it overstates the importance of populism and de-democratization in public opinion research. The second part of the chapter returns to the book's otherwise standard approach to presenting insightful coverage of topics such as elite opinion, new social issues, the unique role of a two-party system (in the US) and finally a focus on public support for democracy, which should predict the future of representative democracy as promised at the outset of the chapter.

Without a conclusion, introduction of any cover materials, the book's title is misleading or confusing. As long as readers pick up the book without planning for a single narrative, and are mostly interested in a US-centered, survey research perspective, they should find value in its pages. For better or worse, the book represents the status quo of public opinion research, like many other areas of research, dominated by US, English-speaking, Western academics and institutions. This is no fault of Weakliem, he essentially summarizes his extensive knowledge on the state of the art of the past century of public opinion research. Still, if we are interested in leveling the scientific playing field and embracing global, interconnected science, we should raise questions if not demands to shift the focus toward the Global South and integrating theoretical perspectives from outside the Western-dominated echo chamber each time a new US-centric book is published - even a potentially useful book such as this one.

Note: Doctoral researchers Hung H.V. Nguyen and Lisa Heukamp provided helpful comments for this review, and I am grateful to the keen editorial eye of Travis Ridout.

Cramer, Katherine J. 2016. The Politics of Resentment: Rural Consciousness in Wisconsin and the Rise of Scott Walker. Chicago, I.L., U.S.A: University of Chicago Press.

Eger, Maureen A., and Nate Breznau. 2017. "Immigration and the Welfare State: A CrossRegional Analysis of European Welfare Attitudes." International Journal of Comparative Sociology 58(5):440-463. doi: 10.1177/0020715217690796.

Eger, Maureen A., and Sarah Valdez. 2015. "Neo-Nationalism in Western Europe.” European Sociological Review 31(1):115-130. doi: 10.1093/esr/jcu087.

Kulin, Joakim, Maureen A. Eger, and Mikael Hjerm. 2016. "Immigration or Welfare? The Progressive's Dilemma Revisited.” Socius 2:1-15. doi: 10.1177/2378023116632223.

Lippmann, Walter. 1997. Public Opinion. original publication 1922. New Brunswick, N.J., U.S.A: Transaction Publishers.

Theocharis, Yannis, and Andreas Jungherr. 2020. “Computational Social Science and the Study of Political Communication.” Political Communication 0(0):1-22. doi:

10.1080/10584609.2020.1833121.

Zaller, John R. 1992. The Nature and Origins of Mass Opinion. Cambridge, UK: Cambridge University Press. 